\title{
EFISIENSI VS IDEALISME DALAM PENGELOLAAN PENDIDIKAN TINGGI
}

\author{
Oleh: Argo Pambudi \\ argo_pambudi@uny.ac.id
}

\section{Abstrak}

Masalah pengelolaan Pendidikan Tinggi di Indonesia masih tetap bergerak diantara 2 pokok persoalan, yaitu masalah manajemen dan masalah akademik. Kedua masalah ini saling berkaitan. Disatu sisi pengelolaan pendidikan tinggi dituntut untuk meningkatkan efisiensi demi memenangkan kompetisi, namun karena lembaga tersebut juga mengemban nilai-nilai idealisme pendidikan maka efisiensi pengelolaan pendidikan tinggi tidak boleh mendominasi pengukuran keberhasilannya. Implementasi nilai-nilai efisiensi sening tidak sejalan - bahkan berkontradiksi - dengan nilai-nilai idealisme yang harus dikembangkannya. Maka dari itu masih banyak ukuran-ukuran lain yang harus dipertimbangkan secara lebih seksama dalam pengelolaan PT tersebut. Tulisan ini berusaha mendeskripsikan struktur permasalahan pengelolaan pendidikan tinggi yang mengandung kontradiksi tersebut.

\section{Pendahuluan}

Dirjen Pendidikan Tinggi Departemen Pendidikan Nasional melalui suratnya yang ditujukan kepada seluruh Rektor PTN, Ketua Sekolah Tinggi Negeri, Direktur Politeknik Negeri, Koordinator Kopertis Wilayah I - XII dan Ketua Pengurus Pusat APTISI di Indonesia telah memohon agar PTN dan PTS tidak mengajukan usul pembukaan Program Studi baru dan/atau pengembangan kelemba-gaannya ke Direktorat Jenderal Pendidikan Tinggi. Dirjen Pendidikan Tinggi sedang menyusun (ulang) tata cara dan tata laksana perijinan pembukaan Program Studi baru.

Menurut data yang diperoleh dari Badan Pusat Statistik (BPS), tercatat jumlah PTS diseluruh Indonesia per Desember 1999 ada 1558 buah, sebagian besar berbentuk Akademi dan Sekolah Tinggi. Jumlah Program Studi yang diselenggarakannya sebesar 6517 Program Studi. Dalam tahun tersebut, yaitu tahun 1999 telah meluluskan 230.915 orang lulusan. Lokasi dan populasi PTS terbesar berada di DKI Jakarta, Jawa Barat dan Jawa Timur. Sementara itu berkaitan 
dengan keberadaan PTN per September 1999 tercatat data bahwa produksi PTN dalam meluluskan peserta didiknya sebesar 277.289 luiusan program diploma dan 78.045 lulusan program sarjana, termasuk didalamnya lulusan Universitas Terbuka (UT). Dominasi lulusan PTN adalah pada bidang ilmu sosial dan bidang pendidikan. Selanjutnya data yang menunjukkan produk pendidikan tinggi yang menganggur tercatat cukup tinggi. Menunt data yang diperoleh dari BPS antara tahun 1997 - 1999 tingkat pengangguran berpendidikan Diploma I/II berturutturut : 37.676 orang (1997), 47.380 orang (1998) dan 90.230 orang (1999). Untuk tingkat pengangguran yang berpendidikan Diploma III berturut-turut: 104.054 orang (1997), 128.037 orang (1998) dan 153.696 orang (1999). Sementara itu untuk penganggur yang berpendidikan Sarjana tercatat 236.352 orang (1997), 254.111 orang (1998) dan 310.947 orang (1999).

Deskripsi data diatas kiranya dapat menunjukkan betapa besar problema yang dihadapi dunia pendidikan tinggi pada umumnya di Indonesia. Paling tidak data tersebut (diharapkan) mampu menyadarkan berbagai fihak tentang masih adanya kondisi yang perlu pembenahan serius dalam penyelenggaraan PT di Indonesia.

Apabila direnungkan secara lebih seksama deskripsi data diatas, sebenamya belum mencerminkan struktur problema PT di Indonesia secara utuh, namun baru menunjukkan sebagian problema yang tampak dipermukaan saja. Ibarat sebuah gunung es ditengah lautan, pada kenyataannya bagian yang berada dibawah permukaan jauh lebih besar dan justru memiliki peranan lebih sentral karena menopang keberadaan bagian yang nampak di permukaan tersebut. Tulisan ini mencoba mendeskripsikan bagian gunung es masalah pengelolaan PT di Indonesia yang berada dibawah permukaan tersebut.

\section{Efisiensi vs Idealisme}

Agak berbeda sifatnya dengan pendidikan dasar dan pendidikan menengah umum. Disadari atau tidak pencetakan lulusan pendidikan tinggi secara terus-menerus tanpa memperhatikan penyerapan lulusannya di dunia kerja, atau menciptakan lulusan yang menganggur merupakan suatu pemborosan (inefisiensi). Namun disisi yang lain nafsu mendirikan PT di Indonesia itu dapat dibaca sebagai manifestasi idealisme penyelenggara PT yang bersangkutan, yaitu "demi peningkatan harkat dan martabat bangsan yang memang harus diwujudkan.

Dalam bahasa metodologi, problema pengeiolaan PT yang terlihat dipermukaan, seperti hasil interpretasi data dimuka, sebenamya 
merupakan kondisi akibat dari variabel-variabel yang mendahuluinya. Artinya, dalam konteks keberadaan kondisi tersebut pasti terdapat faktorfaktor pendahulu yang menopang keberadaannya. Pertanyaan yang kemudian muncul adalah: Faktorfaktor apa saja yang menyebabkan atau menopang keberadaan masalah pengelolaan PT itu ? Kiranya upaya menggali akar permasalahan yang tidak terlihat di permukaan tersebut dapat lebih memperjelas duduk persoalan (substantive problem) yang sesungguhnya secara utuh. Upaya ini kiranya sangat penting dalam rangka urun rembuk penyusunan kebijakan pembenahan PT secara lebih konsepsual dan efektif.

Dari pengamatan yang dilakukan, kiranya problematika pengelolaan PT di Indonesia dewasa ini masih tetap bergerak disekitar 2 pokok persoalan, yaitu masalah manajemen dan masalah akademik. Kedua dimensi problema ini saling berkaitan, kadang-kadang tidak sejalan, dan bahkan saling bertentangan. Disatu sisi pengelola PT ingin mencapai cita-cita ideal akademisnya, namun kenyataan memaksa manajemen untuk melakukan upaya efisiensi demi mempertahankan hidup lembaga PT yang bersangkutan, dan selebihnya demi memenangkan kompetisi yang cenderung ketat diantara sesama PT itu sendiri. Pemecahan permasalahan ini tidak mungkin dilakukan secara intern olen aktor yang berada didalam PT itu sendiri, namun dipertukan intervensi pemerintah sebagai pemegang monopoli kebijakan regulasi kompetisi (competitive regulatory policy) dan proteksi (protective regulatory policy) untuk meningkatkan kualitas iklim bagi kehidupan institusi PT yang sehat.

Pada awal perkembangannya, kebanyakan perguruan tinggi di indonesia, baik PTN maupun PTS lahir dan berkembang di kota-kota besar. PTN ada di pusat kota, sementara itu PTS berada disekitarnya. Mengapa ? Karena pada awal perkembangannya secara akademis PTS hampir selalu tergantung pada Perguruan Tinggi pembina yang kebanyakan dipegang oleh PTN di kota besar tersebut. Jadi jarang sekali ada PTS berada di kawasan jauh dari lokasi PTN pembina berada. Kenyataan ini menyebabkan profil penyebaran Perguruan Tinggi di Indonesia tidak merata. Populasi terbesamya selalu berada di kotakota besar dan sekitamya. Lokasi geografis pedesaan yang jauh dari kota besar jarang ada yang memilikj Perguruan Tinggi. Banyaknya jumlah PT di Indonesia dengan profil penyebaran yang tidak merata seperti itu mendorong munculnya iklim persaingan yang tidak sehat dikawasan yang padat PT, sementara itu di pedesaan hampir tidak terdapat aktivitas legal pendidikan tinggi. 
Sebagai contoh di kawasan DIY yang pactat PT dewasa ini terdapat tidak kurang dari 70 buah PT dengan tidak kurang dari 267 program studi. yang diselenggarakan. Jumlah ini mengindikasikan adanya persaingan yang ektra ketat antara PT-PT tersebut dalam mendapatkan mahasiswa baru. Terkecuali PTN yang telah mampu hidup mapan dengan dana APBN, bagi PTS, sumber dana dari mahasiswa dewasa ini masih merupakan andalan utama bagi pembiayaan operasional dan pengembangan Perguruan Tinggi yang bersangkutan. Pendapatan dari sumber lain kiranya belum bisa diharapkan. Dengan demikian diantara PTS di lokasi yang padat PT persaingan sudailı menjadi bagian dan hidup. Dewasa - ini kiranya persaingan sudah mengarah ke kondisi yang tidak sehat. Hukum rimba sudah mulai tercium aromanya dalam persaingan PT dalam mendapatkan mahasiswa baru, siapa kuat itulah yang harus menang. Upaya efisiensi untuk memenangkan kompetisi sudah merebak kesemua lini, dan mulai melampaui batas-batas etika yang sebelumnya tabu untuk dilanggar. Kita tentu masih ingat adainya kasus heboh karena sebuah PT berjanji akan memberikan komisi kepada Kepala SLTA yang anak didlknya berhasil digiring masuk ke PT yang bersangkutan. Kalau dahulu kita tidak pernah menjumpai iklan promosi PT lewat radio atau layar
TV, dewasa ini sering kita jumpai promosi PT di layar TV sejajar dengan iklan sandal atau obat nyamuk. Kebijakan pemerintah terus saja dicari celah-celah kelemahannya demi peningkatan efisiensi pengelolaan perguruan tinggi, misalnya: Lembaga tes masuk PT tidak didaya-gunakan untuk menjaring kualitas input, namun lebih banyak digunakan untuk pengumpulan dana sebanyak-banyaknya; Pembukaan program perkuliahan jarak jauh, pembukaan cabang perguruan tinggi di daerah lain, penyelenggaraan perkuliahan program "week end", dan lain sebagainya yang kesemuanya itu berbau pelanggaran kebijakan pemerintah dan etika ideal. Beberapa contoh itu mengindikasikan betapa ketatnya persaingan diantara sesama PT dalam mendapatkan mahasiswa baru. Dengan demikian berbagai kemungkinan akibat yang lebih buruk bagi dunia pendidikan tinggi di Indonesia dapat timbul.

Untuk Perguruan Tinggi Swasta (PTS) kecil yang kalah bersaing, jangankan untuk membayar program pengembangan, seperti mengirim staf dosennya ke jenjang pendidikan yang lebih tinggi (S-2 dan S-3), untuk membiayai kegiatan rutinnya saja, seperti gaji dosen dan karyawan, tunjangan fungsional, honorarium mengajar, program penelitian dan sebagainya, sumber dana dari sedikit mahasiswa tidak mencukupi. 
Bagaimana bisa berkembang ? Bagaimana bisa efektif dan efisien ? Bagaimana bisa mencapai idealisme ? Kemungkinan yang paling jelek adalah PTS yang bersangkutan gulung tikar. Dalam hal pembubaran, lembaga perguruan tinggi berbeda dengan perusahaan. Karena yang dikelola adalah anak-anak manusia maka banyak pertimbangan-pertimbangan sosial politis yang tidak mengijinkannya. Jadi untuk PTS yang mengalami masalah kekurangan dana tersebut paling-paling menjadi merana, lesu darah sepanjang masa. Pembubaran secara drastis dan tiba-tiba, seperti pembubaran sebuah perusahaan, hampir tidak pernah terjadi - tepatnya tidak boleh terjadi. Minimnya gaji dan honorarium mengajar serta tunjangan fungsional dosen dan karyawan PTS yang tidak sepadan dengan beban tugas berakibat pada terpecahnya konsentrasi berfikir para staf dosen dan karyawan tersebut. Staf dosen dan karyawan akan mencari altematif pekerjaan yang lain. Menggantungkan hidup $100 \%$ di PTS miskin sangat tidak mungkin. Berbeda dengan dosen PTN dan PTS kaya yang bisa mencari penghasilan tambahan di PT yang lain, dosen PTS kecil hampir tertutup kemungkinannya untuk mengajar di PT lain. Selanjutnya dosen PTS miskin tersebut akan mencari tambahan penghasilan di bidang nonakademis sebagai penghasilan po- kok. Kini pekerjaan sebagai dosen PTS kecil dianggapnya sebagai pekerjaan sambilan.

\section{Terpecahnya konsentrasi ber-}

fikir para staf dosen di PTS ini kemudian akan menurunkan semangat profesionalisme dan merusak iklim yang kondusif untuk melaksanakan Tri Dharma Perguruan Tinggi secara optimal. Kemudian akan merusak pula idealisme yang seharusnya mereka tegakkan. Komitmen yang dulu mendasari mereka dalam memilih dosen sebagai profesinya sedikit banyak akan luntur dimakan kenyataan hidup yang serba susah. Ringkasnya PTS miskin tersebut akan menghadapi kelangkaan aktivitas akademis yang membutuhkan pembiayaan tinggi. Kiranya masalah terakhir inilah yang merupakan masalah akademis bagi pengembangan perguruan tinggi, khususnya PTS yang telah disebut dimuka.

Berkaitan dengan dominasi jumlah lulusan program studi ilmu sosial dan Kependidikan, sebagian besar memang disebabkan oleh pertimbangan faktor besamya biaya penyelengaraan per program studi ilmu eksakta dan teknologi (unit cost). Dibandingkan dengan unit cost pengelolaan program studi ilmu sosial dan kependidikan, unit cost untuk penyelenggaraan program studi ilmu eksakta dan teknologi jauh lebih besar. Karena itu walaupun lulusan program studi ilmu eksakta 
dar teknoiogi amat dibutuhkan bagi pambengunan bangsa Indonesia dewasa ini, pertimbangan efisiensi tetap mengatakan program studi ini kurang menarik untuk diselengarakan PTS. PTS tetap lebih tertarik mengelola bidang studi yang biaya operasionalnya murah, yaitu ilmu sosial dan kependidikan.

Daya tarik untuk menyelenggarakan program studi ilmu sosial dan kependidikan ini diperkuat lagi oleh kondisi besarnya calon input atau potensi pasar yang ada dalam masyarakat. Kita ketahui bahwa pada umumnya jumlah siswa SLTA jurusan IPS jauh lebih banyak deripada siswa dari jurusan IPA. Sementara itu kebijakan pemerintah mengijinkan lulusan SLTA jurusan IPA dapat melanjutkan studi pada bidang eksakta sekaligus bidang sosial di PT. Hal ini tentu berpengaruh pada jauh lebih banyaknya animo calon mahasiswa untuk memasuki bidang studi ilmu sosial dan kependidikan. Jadi wajarlah kalau kemudian jumlah lulusan PT didominasi sarjana bidang ilmu sosial dan kependidikan.

Menurut catatan penulis, program studi teknologi yang jumlahnya relatif sedikit di Universitas itupun kondisi kehidupannya banyak yang kurang menggembirakan. Pengelolaannya dihadapkan pada kondisi yang sulit untuk mencapai tingkat efisiensi yang tinggi. Mengapa ? Antara lain, karena peraturan pemerintah tentang pendidikan tinggi menetapkan bahwa setiap perguruan tinggi yang berbentuk Universitas di samping menyelenggarakan program studi îmu sosial juga harus menyelenggarakan program studl eksakta dan teknologi. Padahal tidak semua universitas itu memiliki sumber daya yang memadai untuk menyelenggarakan program studi tersebut secara baik. Karena itu pada universitas yang demikian program studi teknologi yang diselenggarakan selalu menjadi beban yang memerlukan subsidi dari program studi lain yang surplus. Biasanya program studi yang surplus adalah program studi bidang ilmu sosial, misalnya: program studi IImu Ekonomi, Hukum dan sebagainya. Dengan demikian himbauan dari berbagai fihak yang menganjurkan agar PT memprioritaskan pengembangan program studi teknologi sulit untuk dilaksanakan, terutama oleh PTS.

\section{Peranan Pemerintah}

Dengan pemahaman substansi problem pengelolaan PT seperti itu, maka dapat disimpulkan bahwa pembenahan pengelolaan PT di Indonesia agar bisa efisien dan sekaligus mampu menjunjung nilainilai ideal dunia pendidikan tidak bisa tidak harus melibatkan peranan pemerintah secara aktif. Tidak mungkin masalah pengelonaan PT 
itu diatasi sendiri olah institusi PT yang bersangkutan.

Khusus yang berkaitan dengan peranan pemerintah melalui PTN sebagai perguruan tinggi pembina, dewasa ini temyata belum efektif untuk menciptakan efisiensi sekaligus menjunjung idealisme pendidikan dalam pengelolaan PT di Indonesia. Kita ketahui bahwa dengan semakin terbatasnya anggaran pemerintah untuk membiayai PTN maka pemerintah membuat kebijakan yang memberikan kebebasan lebih besar pada PTN untuk mengumpulkan dana bagi aktivitasnya. Apa yang terjadi kemudian ? Banyak PTN yang membuka program baru yang sebenarnya bisa dilakukan oleh PTS, seperti program ekstension, Diploma 3, program sore hari dan sebagainya. Akibatnya dengan pembukaan program-program baru tersebut status PTN secara substansial ber-angsur-angsur berubah dari yang seharusnya sebagai pembina menjadi pesaing dalam perebutan calon mahasiswa baru. Dengan demikian jelas PTS kecil, yang sudah terpuruk kekurangan mahasiswa, jelas kalah dan akan semakin terancamlah perkembangannya. Sementara PTN sibuk dengan ekspansi dan deversifikasi program-program baru yang dikelola secara swasta. Fungsi PTN sebagai pembina PT kecil semakin terabaikan. Lebih jauh lagi fungsi-fungsi pokok yang lain, seperti penelitian dan pengernbang- an ilmu ikut tersendat akibat terlampau beratnya prioritas upaya peningkatan efisiensi tersebut.

\section{Penutup}

Melihat struktur permasalahan

yang seperti itu maka jelas pemecahannya tidak bisa dilakukan dengan himbauan kepada penyelenggara untuk melakukan langkahlangkah tertentu. Bagi penyelenggara PT, yang diprioritaskan adalah meningkatkan pelaksanaan asas efisiensi internal kelembagaan, sementara itu untuk merealisasikan idealisme pendidikan tan misi-misi pemerintah yang lain intervensi pemerintah harus lebih dikedepankan. Dengan demikian pelaksanaan asas efisiensi tidak boleh mendominasi penyelenggaraan PT di Indonesia. Masih banyak ukuranukuran lain yang perlu dipertimbangkan secara lebih seksama diantaranya ukuran efektivitas (efectiveness), keadilan (equity), kecukupan (adequacy), ketepatan (appropriateness), dan pertanggung-jawaban pada masyarakat (responsibility)

\section{Daftar Pustaka}

Alimi, Anas Syahrul. Dan M. Fadlilah Zaidie (Eds). 1999. Reformasi dan Masa Depan Pendidikan di Indonesia, Sebuah Rekonstruksi Pemikiran Prof. Dr. Djohar, MS. Penerbit IKIP Yogyakarta. 
Biro Pusat Statistik. 2000. Statistik indonesia, Statistical Year Book of indonesia. BPS 2000. Denhardt, Robert B. 1984. Theories of Public Organization. Brook/ Cole Publishing Company. Monterrey. Califomia.

Ditjen Pendidikan Tinggi Departemen Pendidikan dan Kebudayaan RI. 1999. Direkton Pergunuan Tinggi Swasta di Indonesia 1999. Jakarta 1999.

Dunn, William N. 1981. Public Policy Analysis: An Introduction. New York: Prentice-Hall Inc. Englewood Cliffs.

Ripley, Randall B. 1985. Policy Analysis in Political Science. Nelson-Hall Publisher nh. Chicago.

Wahab, Abdul Solichin. 1991. Analisis Kebijaksanaan, dari formulasi ke Implementasi Kebijaksanaan Negara. Bumi Aksara. Jakarta

\section{Biodata Penulis}

Drs. Argo Pambudi, M.Si. lahir di Yogyakarta. Lulus S-1 (1986) dan S-2 (1995) bidang Ilmu Administrasi Negara pada Universitas Gadjah Mada Yogyakarta. Sejak tahun 1999 diangkat menjadi PNS staf pengajar pada Fakultas IImu Sosial Universitas Negeri Yogyakarta. 